\title{
Identifying Sources of Health Care Underutilization Among California's Immigrants
}

\author{
Jocelyn T. Chi • Mark S. Handcock
}

Received: 29 January 2014 / Revised: 23 May 2014 / Accepted: 30 June 2014 /Published online: 12 July 2014

(C) W. Montague Cobb-NMA Health Institute 2014

\begin{abstract}
Many studies show that immigrants face significant barriers in accessing health care. These barriers may be particularly pronounced for newer immigrants, who may face additional obstacles in navigating the health care system. Understanding the sources of health care disparities between recent and non-recent immigrants may allow for better design of policies and interventions to address the vulnerabilities unique to different subgroups of immigrants defined by their length of residency. This study employs descriptive analyses and multivariate logistic regression to estimate the likelihood of accessing and utilizing health care services based on immigration-related factors after controlling for predisposing, enabling, and health care need factors. We also employ a regression-based decomposition method to determine whether health care differences between recent and non-recent immigrants are statistically significant and to identify the primary drivers of healthcare differences between recent and nonrecent immigrants. The findings support the hypothesis that significant disparities in health care access and utilization exist between recent and non-recent immigrants. We found that health care access and utilization differences between recent and non-recent immigrants were driven primarily by enabling resources, including limited English proficiency (LEP), insurance status, public assistance usage, and poverty level. These results indicate that not only are newer immigrants more likely to underutilize health care, but also that their underutilization is driven primarily by their lack of insurance, lack of adequate financial resources, and inability to navigate the health care system due to LEP. The results further indicate that
\end{abstract}

J. T. Chi $(\bowtie)$

Rice University, Houston, TX, USA

e-mail: jocelynchi@alum.berkeley.edu

M. S. Handcock

University of California, Los Angeles, CA, USA

e-mail: handcock@stat.ucla.edu immigrants with prolonged LEP may be less likely to have a usual source of care and more likely to report delays in obtaining medical treatments, than even recent immigrants with LEP.

Keywords Immigration · Recent immigrants $\cdot$ Health care access $\cdot$ Health care utilization $\cdot$ Health care disparities . Health care barriers

\section{Introduction}

Many studies show that immigrants face significant barriers in accessing health care. These barriers include lack of language proficiency $[3,5,15,39,46]$, inability to afford health care [32, 43], lack of transportation to health services [37, 44], and lack of information about health conditions and services [3, 31, 4].

Recent immigrants may experience additional difficulties including job insecurities, legal instabilities, housing difficulties, social isolation, discrimination, and inability to access public assistance [6-9, 25, 27, 41]. Consequently, newer immigrants may face unique challenges in navigating the health care system leading to underutilization of health services. Not surprisingly, length of residency has been found to be a significant predictor of health care utilization among immigrants [24].

Understanding the sources of health care disparities between recent and non-recent immigrants may allow for better design of policies and interventions to address the vulnerabilities unique to different subgroups of immigrants defined by their length of residency. Although many studies have focused on immigrant health care barriers [15-17, 24, 31, 32, 47, 48], comparatively little work has been done to understand the differences in how immigrant health care utilization varies with heterogeneity stemming from differences in length of residency, particularly differences between recent and nonrecent immigrants. 
We use the Andersen behavioral model to guide our study design and to identify areas of equitable and inequitable health care use among immigrants $[1,2]$. This model was introduced in the 1960s to identify factors that predict health services use, to determine equitable health care access, and to foster the development of policies stimulating equitable access [2]. Its fundamental postulation is that an individual's health service use is primarily a function of three classes of factors: (1) factors predisposing health service use (predisposing factors), (2) factors enabling health service use (enabling factors), and (3) factors indicating need for health services (need factors). The classification of health care use predictors into these three classes provides a means of evaluating access equity. According to the model, access is deemed equitable when demographic and need factors drive health services use, and access is inequitable when enabling factors determine utilization [2]. Since its introduction, the model has been revised to account for refinements on the measures included in the three factor classes and to include metrics for access effectiveness [2].

Since this study focuses on disparities in health care access and utilization among immigrants based on heterogeneity stemming from length of residency, we employ this model to identify control variables for our multivariate logistic regression analyses. Just as control variables are used in biological experiments to control for possible confounding, we examine whether the relationships between health care access and utilization and immigration-related factors are statistically significant when predisposing, enabling, and need factors are the same across individuals. We also employ the model to identify possible predictors of the differences in health care access and utilization between recent and non-recent immigrants, to evaluate the results of our analyses, and to ascertain areas of inequitable health care access among immigrants.

\section{Materials and Methods}

\section{Study Design}

We hypothesize that significant health care disparities exist between recent and non-recent immigrants, and employ descriptive analyses and multivariate logistic regression to estimate the likelihood of accessing and utilizing health care services based on immigration-related factors after controlling for predisposing, enabling, and health care need factors. We utilized data from the 2009 California Health Interview Survey (CHIS) [12] for our study. Additional information on how the data were obtained and prepared can be found in the CHIS documentation $[11,13]$. We also present a brief overview in the "Data" section below.

We employ a regression-based decomposition method to determine whether health care differences between recent and non-recent immigrants are statistically significant and to identify variables driving the variation in utilization between these two groups. We use the Andersen behavioral model to guide model specification throughout our study and to identify areas of equitable and inequitable health care use among immigrants $[1,2]$ based on the results of our decomposition analyses.

\section{Data}

Data for this study were obtained from the 2009 California Health Interview Survey (CHIS) [12]. The CHIS is a population-based random-dial telephone survey conducted biennially in California. Surveying over 50,000 Californians, the CHIS is considered the largest state health survey in the nation. The 2009 adult survey was conducted between September 2009 and April 2010 and was administered in six languages based on an English proficiency analysis of the 2000 Census data. The 2009 survey was completed by 47,614 adults, 42,682 of which were from the landline random-digit-dial (landline RDD) sample, 1,885 of which were from a surname sample designed to increase the representation of Koreans and Vietnamese, and 3,047 of which were from a cell phone sample designed to account for households without landlines. Despite potential sampling bias concerns due to RDD sampling, the CHIS data is representative of California's non-institutionalized population [11].

Interviews were considered complete when $80 \%$ of the questionnaire had been completed at the end of all follow-up procedures. The adult interview completion rate was $49 \%$ for the landline RDD and $56.7 \%$ for the cell phone sample. These response rates appear consistent with other scientific state telephone surveys [13]. Detailed information regarding the sample design, data collection methods, response rates, imputation methods, and weights for the CHIS can be found in the CHIS documentation [13].

This study utilizes only responses from the 11,481 immigrant adults in the CHIS, identified by selection of foreignborn respondents. We utilized the weights provided in the CHIS data throughout our study.

\section{Dependent Variables}

We selected four dichotomous dependent variables as measures of health care utilization and access: (1) whether or not the respondent had a usual place to go when sick or needing health advice, (2) whether or not the respondent had visited a doctor in the past 12 months, (3) whether or not the respondent had experienced a delay in obtaining prescriptions in the past 12 months, and (4) whether or not the respondent had experienced a delay in obtaining health care treatment in the past 12 months. These variables have been used in previous studies as measures of health care access and utilization [10, 18, 21, 26]. 
Independent Variables

The independent variables of interest in the regression analyses were immigration-related factors, including length of residency, limited English proficiency (LEP), US citizenship, and race. Previous studies have shown that these factors are predictors of health care utilization among immigrants [24, 33]. In order to model how immigrants may adapt and acquire skills necessary to better navigate the health care system over time through English proficiency acquisition, we also include an interaction term between length of residency and LEP.

Inclusion of the interaction term between length of residency and LEP enables modeling of how health care access and utilization may change as immigrants become better able to communicate needs and concerns directly with health services providers and better able to obtain information on the availability and affordability of medical screening and treatments. The interaction term provides a better measure of the skills acquired over time to navigate the health care system than just length of residency on its own since increased length of residency alone does not guarantee acquisition of those skills. For example, social isolation or exclusivity with only those sharing the same native language may both result in failure to acquire information and communication skills necessary for navigating the US health care system, even over long periods of time. Immigrants who fail to develop English proficiency over long periods of time may face unique difficulties in accessing and utilizing health services when compared with other immigrants.

We determined length of residency using self-reported data on the number of years lived in the US and identified recent immigrants as those with fewer than 5 years in the US. Although we could have employed only a binary variable indicating recent or non-recent immigrant status, we elected to retain the categories for length of residency provided in the CHIS data (0 to 4, 5 to 9,10 to 14 , and 15 +years) to allow for different associations between each additional half-decade of residency (until 15 years) and the measures of health care utilization and access. Collapsing length of residency into a binary variable in the multivariate logistic regression models would have been sufficient to identify differences between recent and non-recent immigrants but retention of the higherresolution data further enables the exploration of possible mechanisms for differences due to prolonged LEP.

To identify those with LEP, we regarded respondents who speak English "well" or "very well" as not having LEP and those speaking English "not well" or "not at all" as having LEP. This operationalization has been used to study Latino immigrant health care utilization [10], and we believe that this cut-point realistically models how immigrants who do not speak English, or who speak it poorly, may face significantly greater difficulties in navigating the US health care system than those who speak English well. We utilized the race variable from the Census 2000 definitions; the variable encompasses responses from several self-reported race variables in the CHIS.

\section{Control Variables}

Using the Andersen behavioral model, we identified three primary categories of control variables in the study $[1,2]$. Factors predisposing respondents to obtain health care included age, gender, marital status, education level, employment, and family type. Factors enabling access included current insurance status, public assistance usage, family poverty level, household size, and community type. Additionally, we identified self-reported health status as an indicator of a respondent's need for health care services. These variables have been employed as control variables in previous studies on health care access and utilization [10, 26, 45, 49].

Gender, marital status, and race were operationalized as binary variables while all other control variables were employed as categorical variables due to the nature of the survey responses. Although age could also have been operationalized as a continuous variable, we chose to employ it as a categorical variable by decade to allow for different associations between each decade of age and the measures of health care utilization and access.

\section{Statistical Analyses}

We performed survey-weighted descriptive analyses using Student's $t$-test for continuous variables and the chi-square test for categorical variables to compare characteristics between recent and non-recent immigrants in the data. To adjust for possible limitations due to multiple comparisons in the univariate analyses, we employed Holm-adjusted $p$ values in determining significance $(p<0.05)$. We employed the p.adjust function in the core stats package in R to obtain the Holmadjusted $p$ values $[28,40]$.

We then used multivariate logistic regression to estimate the likelihood of health care utilization based on immigrationrelated factors after controlling for the factors previously described. We used the Zelig package in $\mathrm{R}[29,40]$ to perform the logistic regression analyses, employing the survey weights provided in the CHIS data with significance determined at the $p<0.05$ level. We tested for limitations due to multiple comparisons in our multivariate models using a likelihood ratio test to test the significance of all the variables simultaneously (significance $=p<0.05$ ). We utilized generalized variance inflation factors to test for multicollinearity in the non-control variables in our models [22]. We employed the anova function in the core stats package, the vif function in the car package, and the svyglm function in the survey package in R to compute these diagnostics $[40,23,34]$. 
Finally, we employed the Blinder-Oaxaca decomposition to test whether differences in health care access between recent and non-recent immigrants were statistically significant and to further identify the variables explaining the majority of the variation between these two groups. Throughout the analyses, we employed the weights provided in the CHIS data and determined significance at the $p<0.05$ level.

The Blinder-Oaxaca decomposition is a regression-based technique that partitions the mean difference between groups for a variable of interest into a portion explained by the predicting variables included in the model ("observed") and a portion explained by the coefficients predicted from the regression ("unobserved"). The technique utilizes regression estimates for each of the two groups and sample means from the predicting variables [20]. Since the outcome of interest in the decomposition is the mean difference between the two groups, variables that are significantly correlated with the difference between the groups are considered the primary drivers of the variation between the groups for the variable of interest.

When the mean difference between two groups is statistically significant, the results indicate whether those differences can be attributed to the observed part, unobserved heterogeneity, or both. When the differences due to the observed part are statistically significant, the difference between the two groups in the predicted probability of the outcome variable can be attributed to the factors included in the model. When the differences due to the unobserved part are statistically significant, the same difference can be explained by factors not included in the model. Coefficients on the covariates in the decomposition results correspond to the contribution from each covariate to the difference between the two groups in the predicted probability of the outcome variables [20]. In particular, coefficients on the covariates in the observed and unobserved parts of the decomposition sum up to the differences due to the observed and unobserved parts, respectively. Please refer to Elder et al. [19] and Fairlie [20] for brief technical treatments on the decomposition $[19,20]$.

Although the Blinder-Oaxaca decomposition is frequently used to decompose differences between groups into observed and unobserved parts [10, 14, 35, 36, 38], this study focuses on the observed differences between recent and non-recent immigrants. Accordingly, we utilize the decomposition to test whether or not health care disparities between recent and nonrecent immigrants are significant and to identify the factors driving the observed variation between these two groups. Since our models utilize binary dependent variables, we employed the extension of the Blinder-Oaxaca decomposition technique to logit and probit models proposed in Fairlie [20], and employed the Oaxaca package for Stata and Stata 12 for the analyses [30, 42].

The Andersen behavioral model provides a framework for assessing our decomposition results and identifying areas of equitable and inequitable health care utilization among immigrants based on the primary predictors of actual health care use [2]. Actual use driven by demographic and need factors constitute equitable access while use driven by social structure, beliefs, and enabling characteristics signify inequitable use. We employed this model to assess the equity of the primary drivers of the disparities between recent and nonrecent immigrants.

\section{Results}

\section{Descriptive Analyses}

Table 1 reports the results of the descriptive analyses on characteristics between recent and non-recent immigrants. We found that recent immigrants were less likely than nonrecent immigrants to have a usual place to go when sick, less likely to have had at least one doctor's visit in the previous 12 months, and less likely to be naturalized citizens. Demographically, recent immigrants were more likely than nonrecent immigrants to be younger and single, less likely to participate in SSI, and more likely to be very poor with family income levels at less than $100 \%$ of the federal poverty level. There were also some differences in racial composition between recent and non-recent immigrants groups.

\section{Multivariate Logistic Regression Analyses}

Table 2 reports the results of the multivariate logistic regression analyses for all immigrants with all variables included in each of the four models simultaneously. We found that immigrants living more than 15 years in the US were approximately 2.4 times more likely to have a usual place to go when sick than recent immigrants. Immigrants who had lived in the US between 5 and 9 years and 15 years or more were both approximately $60 \%$ less likely to report experiencing a delay in obtaining treatments when compared with recent immigrants. Immigrants with LEP were $83 \%$ less likely to report experiencing delays in obtaining prescriptions and treatments, compared to immigrants without LEP.

Although non-recent immigrants were more likely to have a usual place to go when sick and less likely to report delays in obtaining medical treatments, we found that this trend was reversed for those who continued to struggle with English proficiency. Among immigrants with LEP, those who had been living in the US for 15 years or more were almost $60 \%$ less likely to have a usual place to go when sick compared with recent immigrants, and compared with recent immigrants with LEP, immigrants with LEP who had lived between 5 and 9 years in the US were approximately four 
Table 1 Survey-weighted descriptive comparisons between recent and non-recent immigrants in California

\begin{tabular}{|c|c|c|c|c|}
\hline & $\begin{array}{l}\text { Recent immigrants } \\
(n=598)\end{array}$ & $\begin{array}{l}\text { Non-recent immigrants } \\
(n=10,883)\end{array}$ & $p$ value & Holm-adjusted $p$ value \\
\hline \multicolumn{5}{|c|}{ Measures of health care access and utilization } \\
\hline Usual place to go when sick & 0.61 & 0.79 & 0.000 & $0.000 * * *$ \\
\hline Visited doctor within past 12 months & 0.66 & 0.77 & 0.005 & 0.175 \\
\hline Delay in obtaining prescriptions & 0.05 & 0.08 & 0.064 & 1.000 \\
\hline Delay in obtaining medical treatment & 0.13 & 0.11 & 0.596 & 1.000 \\
\hline \multicolumn{5}{|l|}{ Immigration-related factors } \\
\hline Limited English proficiency (LEP) & 0.56 & 0.43 & 0.010 & 0.320 \\
\hline Naturalized citizen & 0.06 & 0.56 & 0.000 & $0.000 * * *$ \\
\hline \multicolumn{5}{|l|}{ Race } \\
\hline African American & 0.08 & 0.02 & 0.001 & $0.038^{*}$ \\
\hline American Indian/Alaskan Native & 0.02 & 0.01 & 0.062 & 1.000 \\
\hline Asian & 0.35 & 0.28 & 0.062 & 1.000 \\
\hline Multirace & 0.00 & 0.01 & 0.277 & 1.000 \\
\hline Other single race & 0.23 & 0.40 & 0.000 & $0.000 * * *$ \\
\hline Pacific Islander & 0.02 & 0.00 & 0.055 & 1.000 \\
\hline White & 0.30 & 0.29 & 0.865 & 1.000 \\
\hline \multicolumn{5}{|l|}{ Predisposing factors } \\
\hline Age & 33 & 45 & 0.000 & $0.000 * * *$ \\
\hline Male & 0.43 & 0.50 & 0.113 & 1.000 \\
\hline Married & 0.53 & 0.64 & 0.022 & 0.660 \\
\hline \multicolumn{5}{|l|}{ Education } \\
\hline Less than high school & 0.34 & 0.45 & 0.008 & 0.272 \\
\hline High school & 0.21 & 0.21 & 0.886 & 1.000 \\
\hline College & 0.46 & 0.34 & 0.014 & 0.434 \\
\hline Employed & 0.00 & 0.01 & 0.496 & 1.000 \\
\hline \multicolumn{5}{|l|}{ Family type } \\
\hline Married with kids & 0.33 & 0.41 & 0.066 & 1.000 \\
\hline Married, no kids & 0.19 & 0.26 & 0.115 & 1.000 \\
\hline Single adult, $21+$ & 0.33 & 0.25 & 0.051 & 1.000 \\
\hline Single with kids & 0.08 & 0.06 & 0.443 & 1.000 \\
\hline Single young adult, 19-20 & 0.05 & 0.01 & 0.000 & $0.000 * * *$ \\
\hline Single, 18 years old & 0.03 & 0.01 & 0.001 & $0.038^{*}$ \\
\hline \multicolumn{5}{|l|}{ Enabling factors } \\
\hline Currently insured & 0.61 & 0.75 & 0.003 & 0.108 \\
\hline \multicolumn{5}{|l|}{ Public assistance } \\
\hline TANF/CalWorks participation & 0.02 & 0.03 & 0.439 & 1.000 \\
\hline Food stamps participation & 0.07 & 0.07 & 0.934 & 1.000 \\
\hline SSI participation & 0.00 & 0.04 & 0.000 & $0.000 * * *$ \\
\hline WIC participation & 0.10 & 0.06 & 0.038 & 1.000 \\
\hline Medical participation & 0.21 & 0.18 & 0.507 & 1.000 \\
\hline \multicolumn{5}{|c|}{ Family poverty level (\% of Federal Poverty Level) } \\
\hline 0-99 \% FPL & 0.44 & 0.26 & 0.000 & $0.000 * * *$ \\
\hline 100-199 \% FPL & 0.18 & 0.26 & 0.038 & 1.000 \\
\hline 200-299 \% FPL & 0.11 & 0.13 & 0.347 & 1.000 \\
\hline $300 \%$ FPL and above & 0.27 & 0.35 & 0.124 & 1.000 \\
\hline Household size & 4.02 & 3.89 & 0.064 & 1.000 \\
\hline \multicolumn{5}{|l|}{ Community type } \\
\hline Rural & 0.05 & 0.07 & 0.151 & 1.000 \\
\hline
\end{tabular}


Table 1 (continued)

\begin{tabular}{lllll}
\hline & $\begin{array}{l}\text { Recent immigrants } \\
(n=598)\end{array}$ & $\begin{array}{l}\text { Non-recent immigrants } \\
(n=10,883)\end{array}$ & $p$ value & Holm-adjusted $p$ value \\
\hline Suburban & 0.83 & 0.78 & 0.135 & 1.000 \\
Urban & 0.83 & 0.78 & 0.341 & 1.000 \\
Need factor & & & 0.184 & 1.000 \\
Self-reported general health status & 0.20 & 0.15 & 0.739 & 1.000 \\
Excellent & 0.23 & 0.24 & 0.083 & 1.000 \\
Very good & 0.42 & 0.34 & 0.008 & 0.272 \\
Good & 0.14 & 0.23 & 0.100 & 1.000 \\
Fair & 0.02 & 0.05 & \\
Poor & Sur & & \\
\hline
\end{tabular}

Data source: 2009 California Health Interview Survey (CHIS) [12]. Most values expressed as proportions. Age and household size expressed as the mean. Test statistics and $p$ values comparing recent and non-recent Asian immigrants in California were obtained using the chi-square test for categorical variables and Student's $t$-test for continuous variables. Holm-adjusted $p$ values are presented to account for multiple comparisons in univariate testing. $*<0.05 ; * *<0.01 ; * * *<0.001$

times more likely to report experiencing delays in obtaining medical treatment.

Among all immigrants, American Indians, Alaskan Natives, Asians, and others reporting a single race were approximately $70 \%$ less likely to report having had a doctor's visit than African Americans. White immigrants were approximately $60 \%$ less likely to report having had a doctor's visit than African American immigrants. Multirace immigrants were approximately $70 \%$ less likely to report delays in obtaining medical treatment than African American immigrants.

Although we employed predisposing, enabling, and need factors only as control variables in our multivariate logistic regression models, we found that many of them were statistically significantly correlated with the four metrics of health care access and utilization we examined. In particular, we found that age, employment, family status, insurance, public assistance usage, poverty level, community type, and selfreported health status were significantly correlated with health care access and utilization at the $p<0.05$ level. Accordingly, we included the predisposing, enabling, and need factors as variables of interest in our decomposition analyses to identify sources of differences in health care access and utilization between recent and non-recent immigrants.

\section{Decomposition Analyses}

Table 3 shows the results of the Blinder-Oaxaca decomposition analyses. Since the differences due to unobserved heterogeneity were not statistically significant in any of the models, we do not report the coefficients for differences due to unobserved heterogeneity. The predicted probability for having a usual place to go when sick was 59 and $79 \%$ for recent and non-recent immigrants, respectively. The predicted probability for having had a doctor's visit in the previous 12 months was 66 and $77 \%$ for recent and non-recent immigrants, respectively. The differences between recent and nonrecent immigrants were statistically significant in these two metrics of health care access and utilization. By contrast, the differences for delays in prescriptions or other health treatments were not significant.

Differences due to the observed part accounted for $59 \%$ $(0.118 / 0.199)$ of the disparity between recent and non-recent immigrants in having a usual source of care and $43 \%(0.046 /$ 0.106 ) of the disparity in having had a doctor's visit in the previous 12 months. These differences were driven primarily by LEP, age, insurance status, public assistance usage, poverty level, and self-reported general health status. Since only differences due to the observed parts were statistically significant, the results indicate that differences between recent and non-recent immigrants in the predicted probability of having a usual source of care when sick and having had a doctor's visit in the previous 12 months can be explained by the predisposing, enabling, and need factors included in the models.

Among factors in the observed part, several with significant contributions were observed. Among the immigrationrelated factors, differences in English proficiency accounted for 0.011 , or $9.3 \%(0.011 / 0.118)$, of the gap between recent and non-recent immigrants in the predicted probability of having a usual source of care. Among the predisposing factors, differences in age accounted for 0.037 and 0.026 , or $31.4 \%(0.037 / 0.118)$ and $56.5 \%(0.026 / 0.046)$, of the gaps between recent and non-recent immigrants in the predicted probabilities of having a usual source of care and having had a doctor's visit in the previous 12 months, respectively. Among the enabling factors, contributions from insurance status to the gaps between recent and non-recent immigrants in the predicted probabilities for having a usual source of care and 
Table 2 Multivariate logistic regression analyses of immigration-related factors and health care access and utilization among immigrant adults

\begin{tabular}{|c|c|c|c|c|c|c|c|c|}
\hline & \multicolumn{2}{|c|}{$\begin{array}{l}\text { (1) } \\
\text { Usual source }\end{array}$} & \multicolumn{2}{|c|}{$\begin{array}{l}\text { (2) } \\
\text { Doctor visit }\end{array}$} & \multicolumn{2}{|c|}{$\begin{array}{l}\text { (3) } \\
\text { Delay prescr }\end{array}$} & \multicolumn{2}{|c|}{$\begin{array}{l}\text { (4) } \\
\text { Delay treatment }\end{array}$} \\
\hline & OR & $95 \% \mathrm{CI}$ & OR & $95 \% \mathrm{CI}$ & OR & $95 \% \mathrm{CI}$ & OR & $95 \% \mathrm{CI}$ \\
\hline \multicolumn{9}{|l|}{ Immigration-related factors } \\
\hline \multicolumn{9}{|l|}{ Length of residency } \\
\hline \multicolumn{9}{|l|}{$0-4$ years (reference) } \\
\hline 5-9 years & 2.14 & $(0.99-4.62)^{\#}$ & 1.79 & $(0.84-3.81)$ & 0.52 & $(0.17-1.56)$ & 0.39 & $(0.17-0.86)^{*}$ \\
\hline $10-14$ years & 1.93 & $(0.93-4.04)^{\#}$ & 1.69 & $(0.83-3.43)$ & 1.10 & $(0.32-3.81)$ & 0.45 & $(0.18-1.11)^{\#}$ \\
\hline $15+$ years & 2.38 & $(1.16-4.87)^{*}$ & 1.26 & $(0.67-2.39)$ & 1.09 & $(0.40-2.91)$ & 0.42 & $(0.19-0.94) *$ \\
\hline Limited English proficiency (LEP) & 1.17 & $(0.48-2.83)$ & 0.79 & $(0.35-1.78)$ & 0.34 & $(0.10-1.11)^{\#}$ & 0.17 & $(0.06-0.50)^{* *}$ \\
\hline \multicolumn{9}{|c|}{ Interaction between length of residency and LEP } \\
\hline \multicolumn{9}{|l|}{ 0-4 years *LEP (reference) } \\
\hline $5-9$ years $*$ LEP & 0.64 & $(0.23-1.77)$ & 0.76 & $(0.28-2.02)$ & 3.58 & $(0.84-15.22)^{\#}$ & 4.20 & $(1.16-15.16)^{*}$ \\
\hline $10-14$ years $*$ LEP & 0.60 & $(0.22-1.64)$ & 0.72 & $(0.28-1.86)$ & 1.13 & $(0.25-5.06)$ & 2.67 & $(0.80-8.95)$ \\
\hline $15+$ years $*$ LEP & 0.38 & $(0.16-0.93)^{*}$ & 0.90 & $(0.39-2.06)$ & 1.25 & $(0.36-4.32)$ & 3.10 & $(0.97-9.88)^{\#}$ \\
\hline Non-citizen & 0.75 & $(0.56-1.01)^{\#}$ & 0.92 & $(0.70-1.22)$ & 0.94 & $(0.58-1.51)$ & 0.68 & $(0.43-1.07)^{\#}$ \\
\hline \multicolumn{9}{|l|}{ Race } \\
\hline \multicolumn{9}{|l|}{ African American (reference) } \\
\hline American Indian/Alaskan Native & 0.30 & $(0.08-1.15)^{\#}$ & 0.26 & $(0.08-0.78)^{*}$ & 0.37 & $(0.09-1.44)$ & 0.85 & $(0.26-2.82)$ \\
\hline Asian & 0.71 & $(0.21-2.42)$ & 0.26 & $(0.11-0.63)^{* *}$ & 0.56 & $(0.23-1.36)$ & 0.43 & $(0.18-1.03)^{\#}$ \\
\hline Multirace & 1.20 & $(0.27-5.38)$ & 0.48 & $(0.12-1.84)$ & 1.13 & $(0.20-6.30)$ & 0.29 & $(0.09-0.99)^{*}$ \\
\hline Other single race & 0.82 & $(0.25-2.71)$ & 0.31 & $(0.13-0.74)^{* *}$ & 0.64 & $(0.25-1.64)$ & 0.60 & $(0.26-1.40)$ \\
\hline Pacific Islander & 3.55 & $(0.37-33.92)$ & 1.22 & $(0.22-6.82)$ & 0.48 & $(0.04-5.43)$ & 1.24 & $(0.13-11.47)$ \\
\hline White & 0.90 & $(0.27-3.04)$ & 0.41 & $(0.17-0.97)^{*}$ & 0.57 & $(0.24-1.36)$ & 0.68 & $(0.29-1.57)$ \\
\hline \multicolumn{9}{|l|}{ Predisposing factors } \\
\hline \multicolumn{9}{|l|}{ Age } \\
\hline \multicolumn{9}{|l|}{ 18-21 (reference) } \\
\hline $22-29$ & 1.24 & $(0.61-2.52)$ & 2.33 & $(1.06-5.15)^{*}$ & 1.25 & $(0.38-4.10)$ & 1.92 & $(0.60-6.13)$ \\
\hline $30-39$ & 1.63 & $(0.78-3.40)$ & 3.17 & $(1.43-7.05)^{* *}$ & 1.92 & $(0.58-6.33)$ & 1.87 & $(0.60-5.81)$ \\
\hline $40-49$ & 1.99 & $(0.97-4.10)^{\#}$ & 3.64 & $(1.63-8.15)^{* *}$ & 1.74 & $(0.53-5.71)$ & 2.33 & $(0.73-7.44)$ \\
\hline $50-59$ & 2.04 & $(0.97-4.30)^{\#}$ & 3.70 & $(1.64-8.33)^{* *}$ & 1.98 & $(0.59-6.73)$ & 1.46 & $(0.44-4.77)$ \\
\hline $60-69$ & 2.62 & $(1.22-5.65)^{*}$ & 4.75 & $(2.06-10.95)^{* * *}$ & 1.18 & $(0.35-3.96)$ & 0.92 & $(0.27-3.14)$ \\
\hline $70+$ & 3.15 & $(1.40-7.07)^{* *}$ & 4.66 & $(1.98-10.95)^{* * *}$ & 1.31 & $(0.37-4.62)$ & 0.78 & $(0.19-3.19)$ \\
\hline Male & 0.62 & $(0.49-0.79)^{* * *}$ & 0.44 & $(0.39-0.49)^{* * *}$ & 0.93 & $(0.64-1.34)$ & 0.79 & $(0.58-1.09)$ \\
\hline Married & 0.98 & $(0.61-1.57)$ & 1.43 & $(0.85-2.41)$ & 0.70 & $(0.38-1.30)$ & 0.80 & $(0.46-1.39)$ \\
\hline \multicolumn{9}{|l|}{ Education } \\
\hline \multicolumn{9}{|l|}{ Less than high school (reference) } \\
\hline High school & 1.07 & $(0.81-1.42)$ & 0.85 & $(0.65-1.10)$ & 1.13 & $(0.69-1.83)$ & 1.05 & $(0.71-1.56)$ \\
\hline College & 1.12 & $(0.76-1.64)$ & 1.02 & $(0.70-1.49)$ & 1.16 & $(0.73-1.86)$ & 1.09 & $(0.73-1.61)$ \\
\hline Employed & 1.03 & $(0.25-4.31)$ & 2.87 & $(1.09-7.57)^{*}$ & 6.08 & $(1.41-26.24)^{*}$ & 2.80 & $(0.75-10.40)$ \\
\hline \multicolumn{9}{|l|}{ Family type } \\
\hline \multicolumn{9}{|l|}{ Married with kids (reference) } \\
\hline Married, no kids & 1.06 & $(0.75-1.51)$ & 1.41 & $(1.03-1.94)^{*}$ & 1.54 & $(0.87-2.71)$ & 1.34 & $(0.83-2.19)$ \\
\hline Single adult, $21+$ & 0.79 & $(0.46-1.34)$ & 1.70 & $(0.95-3.06)^{\#}$ & 1.28 & $(0.68-2.41)$ & 1.11 & $(0.61-2.01)$ \\
\hline Single with kids & 0.70 & $(0.40-1.26)$ & 1.38 & $(0.72-2.62)$ & 1.16 & $(0.55-2.42)$ & 0.74 & $(0.39-1.43)$ \\
\hline Single young adult, $19-20$ & 0.48 & $(0.14-1.66)$ & 1.62 & $(0.46-5.75)$ & 0.36 & $(0.04-3.06)$ & 1.89 & $(0.38-9.31)$ \\
\hline Single, 18 years old & 0.54 & $(0.18-1.59)$ & 2.86 & $(0.88-9.28)^{\#}$ & 0.19 & $(0.03-1.37)^{\#}$ & 0.19 & $(0.03-1.23)^{\#}$ \\
\hline \multicolumn{9}{|l|}{ Enabling factors } \\
\hline Currently insured & 4.30 & $(3.17-5.83)^{* * *}$ & 3.01 & $(2.31-3.93)^{* * *}$ & 1.80 & $(1.04-3.12)^{*}$ & 0.65 & $(0.40-1.07)^{\#}$ \\
\hline
\end{tabular}


Table 2 (continued)

\begin{tabular}{|c|c|c|c|c|c|c|c|c|}
\hline & \multicolumn{2}{|c|}{$\begin{array}{l}\text { (1) } \\
\text { Usual source }\end{array}$} & \multicolumn{2}{|c|}{$\begin{array}{l}\text { (2) } \\
\text { Doctor visit }\end{array}$} & \multicolumn{2}{|c|}{$\begin{array}{l}\text { (3) } \\
\text { Delay prescr }\end{array}$} & \multicolumn{2}{|c|}{$\begin{array}{l}\text { (4) } \\
\text { Delay treatment }\end{array}$} \\
\hline & OR & $95 \% \mathrm{CI}$ & OR & $95 \% \mathrm{CI}$ & OR & $95 \% \mathrm{CI}$ & OR & $95 \% \mathrm{CI}$ \\
\hline \multicolumn{9}{|l|}{ Public assistance } \\
\hline TANF/CalWorks participation & 0.77 & $(0.38-1.54)$ & 0.53 & $(0.25-1.10)^{\#}$ & 0.87 & $(0.43-1.73)$ & 1.95 & $(0.79-4.82)$ \\
\hline Food stamps participation & 0.90 & $(0.58-1.40)$ & 0.87 & $(0.59-1.28)$ & 0.99 & $(0.59-1.65)$ & 0.98 & $(0.52-1.87)$ \\
\hline SSI participation & 1.76 & $(1.02-3.05)^{*}$ & 1.82 & $(1.10-3.04)^{*}$ & 1.19 & $(0.53-2.65)$ & 0.78 & $(0.32-1.87)$ \\
\hline WIC participation & 0.92 & $(0.57-1.49)$ & 1.34 & $(0.84-2.15)$ & 1.78 & $(0.92-3.43)^{\#}$ & 1.19 & $(0.69-2.07)$ \\
\hline Medical participation & 0.56 & $(0.39-0.82)^{* *}$ & 0.78 & $(0.53-1.15)$ & 0.68 & $(0.40-1.15)$ & 1.14 & $(0.64-2.05)$ \\
\hline \multicolumn{9}{|c|}{ Family poverty level (\% of Federal Poverty Level) } \\
\hline \multicolumn{9}{|l|}{ 0-99 \% FPL (reference) } \\
\hline 100-199 \% FPL & 1.22 & $(0.91-1.62)$ & 0.84 & $(0.63-1.12)$ & 0.60 & $(0.36-1.00)^{* \mathrm{a}}$ & 0.95 & $(0.58-1.55)$ \\
\hline 200-299 \% FPL & 1.81 & $(1.21-2.69)^{* *}$ & 1.31 & $(0.91-1.89)$ & 0.89 & $(0.42-1.91)$ & 0.93 & $(0.47-1.85)$ \\
\hline $300 \% \mathrm{FPL}$ and above & 1.57 & $(1.02-2.40)^{*}$ & 1.30 & $(0.88-1.92)$ & 0.62 & $(0.32-1.21)$ & 1.28 & $(0.66-2.47)$ \\
\hline Household size & 0.99 & $(0.92-1.07)$ & 1.05 & $(0.98-1.13)$ & 1.01 & $(0.88-1.16)$ & 1.00 & $(0.87-1.14)$ \\
\hline \multicolumn{9}{|l|}{ Community type } \\
\hline \multicolumn{9}{|l|}{ Need factor } \\
\hline \multicolumn{9}{|l|}{ Self-reported general health status } \\
\hline \multicolumn{9}{|l|}{ Excellent (reference) } \\
\hline Very good & 1.24 & $(0.82-1.88)$ & 1.06 & $(0.76-1.48)$ & 1.91 & $(1.12-3.27)^{*}$ & 1.77 & $(1.13-2.78)^{*}$ \\
\hline Good & 1.33 & $(0.90-1.96)$ & 1.40 & $(1.03-1.90)^{*}$ & 1.75 & $(1.12-2.75)^{*}$ & 1.65 & $(1.01-2.69)^{*}$ \\
\hline Fair & 1.40 & $(0.92-2.11)$ & 1.82 & $(1.29-2.57)^{* * *}$ & 5.51 & $(3.31-9.18) * * *$ & 3.35 & $(2.01-5.57) * * *$ \\
\hline Poor & 2.39 & $(1.24-4.63)^{* *}$ & 5.04 & $(2.91-8.72)^{* * *}$ & 7.67 & $(4.10-14.33)^{* * *}$ & 5.43 & $(2.40-12.30)^{* * *}$ \\
\hline Constant & 0.74 & $(0.12-4.56)$ & 0.68 & $(0.16-2.93)$ & 0.03 & $(0.00-0.19)^{* * *}$ & 0.25 & $(0.03-1.74)$ \\
\hline Observations & 11,48 & & 11,48 & & 11,48 & & 11,48 & \\
\hline
\end{tabular}

The italics indicate the three classes of factors predicting health services use in the Andersen model

OR odds ratio, $95 \% C I 95 \%$ confidence interval

${ }^{*} p<0.1 ; * p<0.05 ; * * p<0.01, * * * p<0.001$

${ }^{a}$ Confidence interval reported with rounding to two decimal places. Actual values five decimal places are (0.358596-0.997563).

having had a doctor's visit were 0.030 and 0.023 , or $25.4 \%$ $(0.030 / 0.118)$ and $50 \%(0.023 / 0.046)$, respectively. The contribution from having family income levels at $0-99 \%$ of the Federal Poverty Level accounted for 0.015 , or $12.7 \%(0.015 /$ 0.118 ), of the gap between recent and non-recent immigrants in the predicted probability of having a usual source of care. The contributions from SSI participation, fair self-reported health status, and poor self-reported health status accounted for $0.003,0.008$, and 0.006 , or $6.5 \%(0.003 / 0.046), 17.4 \%$ $(0.008 / 0.046)$, and $13 \%(0.006 / 0.046)$, of the gap between recent and non-recent immigrants in the predicted probability of having had a doctor's visit in the previous 12 months, respectively.

\section{Discussion}

This study supports the hypothesis that significant disparities in health care access and utilization exist between recent and non-recent immigrants. The multivariate logistic regression results indicate that in addition to demographic and need factors, actual health care use is predicted by immigrationrelated factors as well as enabling resources. These include length of residency, LEP, the interaction between length of residency and LEP, citizenship, race, insurance status, public assistance participation, and poverty level.

When focusing attention on the differences between recent and non-recent immigrants, however, the decomposition results show that only LEP, age, insurance status, public assistance usage, poverty level, and self-reported health status are significant in explaining health care differences between recent and non-recent immigrants.

Using the framework for identifying equitable and inequitable use developed in the Andersen model [2], we find that health care differences between recent and non-recent immigrants are primarily driven by enabling resources (e.g., LEP, insurance status, public assistance usage, and poverty level) pointing to inequitable use. The results show that not only are 
Table 3 Decomposing differences in health care access and utilization between recent and non-recent immigrant adults

\begin{tabular}{|c|c|c|c|c|c|c|c|c|}
\hline & \multicolumn{2}{|l|}{ (1) } & \multicolumn{2}{|l|}{$(2)$} & \multicolumn{2}{|l|}{ (3) } & \multicolumn{2}{|l|}{ (4) } \\
\hline & \multicolumn{2}{|c|}{ Usual source } & \multicolumn{2}{|c|}{ Doctor visit } & \multicolumn{2}{|c|}{ Delay prescr. } & \multicolumn{2}{|c|}{ Delay treatment } \\
\hline & Coef. & $\mathrm{SE}$ & Coef. & SE & Coef. & SE & Coef. & SE \\
\hline \multicolumn{9}{|l|}{ Predicted probability } \\
\hline Non-recent immigrants & 0.793 & $(0.01) * * *$ & 0.769 & $(0.01) * * *$ & 0.077 & $(0.01) * * *$ & 0.113 & $(0.01) * * *$ \\
\hline Recent immigrants & 0.593 & $(0.04) * * *$ & 0.663 & $(0.03) * * *$ & 0.077 & $(0.47)$ & 0.133 & $(0.02) * * *$ \\
\hline \multicolumn{9}{|l|}{ Difference in predicted probability } \\
\hline Total difference & 0.199 & $(0.04) * * *$ & 0.106 & $(0.04) * *$ & 0.001 & $(0.47)$ & $(0.020)$ & $(0.03)$ \\
\hline Differences due to observed part & 0.118 & $(0.03) * * *$ & 0.046 & $(0.02) *$ & 0.021 & $(0.01) * *$ & 0.008 & $(0.02)$ \\
\hline Differences due to unobserved heterogeneity & 0.082 & $(0.04)$ & 0.061 & $(0.04)$ & $(0.021)$ & $(0.47)$ & $(0.029)$ & $(0.02)$ \\
\hline \multicolumn{9}{|l|}{ Observed part } \\
\hline \multicolumn{9}{|l|}{ Immigration-related factors } \\
\hline Limited English proficiency (LEP) & 0.011 & $(0.01) *$ & 0.006 & $(0.00)$ & 0.006 & $(0.00)$ & 0.006 & $(0.01)$ \\
\hline Naturalized citizen & 0.021 & $(0.01)$ & $(0.001)$ & $(0.01)$ & 0.002 & $(0.01)$ & 0.012 & $(0.01)$ \\
\hline \multicolumn{9}{|l|}{ Race } \\
\hline African American & 0.004 & $(0.01)$ & $(0.007)$ & $(0.01)$ & 0.000 & $(0.00)$ & $(0.006)$ & $(0.01)$ \\
\hline American Indian/Alaskan Native & 0.003 & $(0.00)$ & 0.001 & $(0.00)$ & 0.001 & $(0.00)$ & $(0.001)$ & $(0.00)$ \\
\hline Asian & 0.007 & $(0.01)$ & 0.007 & $(0.01)$ & 0.004 & $(0.00)$ & $(0.002)$ & $(0.00)$ \\
\hline Multirace & - & - & - & - & - & - & - & - \\
\hline Other single race & $(0.013)$ & $(0.01)$ & $(0.011)$ & $(0.01)$ & $(0.006)$ & $(0.01)$ & 0.009 & $(0.01)$ \\
\hline Pacific Islander & $(0.002)$ & $(0.00)$ & $(0.002)$ & $(0.00)$ & 0.001 & $(0.00)$ & $(0.001)$ & $(0.00)$ \\
\hline White & 0.000 & $(0.00)$ & 0.000 & $(0.00)$ & 0.000 & $(0.00)$ & $(0.000)$ & $(0.00)$ \\
\hline \multicolumn{9}{|l|}{ Predisposing factors } \\
\hline Age & 0.037 & $(0.01) * * *$ & 0.026 & $(0.01) * *$ & $(0.001)$ & $(0.01)$ & $(0.014)$ & $(0.01)$ \\
\hline Male & $(0.006)$ & $(0.00)$ & $(0.010)$ & $(0.01)$ & $(0.000)$ & $(0.00)$ & $(0.001)$ & $(0.00)$ \\
\hline Married & $(0.001)$ & $(0.00)$ & 0.006 & $(0.01)$ & $(0.002)$ & $(0.00)$ & $(0.001)$ & $(0.00)$ \\
\hline \multicolumn{9}{|l|}{ Education } \\
\hline Less than high school & $(0.003)$ & $(0.00)$ & $(0.001)$ & $(0.00)$ & $(0.001)$ & $(0.00)$ & $(0.001)$ & $(0.00)$ \\
\hline High school & $(0.000)$ & - & $(0.000)$ & $(0.00)$ & $(0.000)$ & - & $(0.000)$ & - \\
\hline College & - & - & - & - & - & - & - & - \\
\hline Employed & $(0.000)$ & - & 0.000 & $(0.00)$ & 0.000 & - & 0.000 & - \\
\hline \multicolumn{9}{|l|}{ Family type } \\
\hline Married with kids & 0.011 & $(0.01)$ & $(0.005)$ & $(0.01)$ & 0.012 & $(0.01)$ & 0.015 & $(0.01)$ \\
\hline Married, no kids & 0.009 & $(0.01)$ & $(0.001)$ & $(0.01)$ & 0.012 & $(0.01)$ & 0.013 & $(0.01)$ \\
\hline Single adult, $21+$ & $(0.008)$ & $(0.01)$ & $(0.002)$ & $(0.01)$ & $(0.013)$ & $(0.01)$ & $(0.015)$ & $(0.01)$ \\
\hline Single with kids & $(0.001)$ & $(0.00)$ & 0.000 & $(0.00)$ & $(0.002)$ & $(0.00)$ & $(0.002)$ & $(0.00)$ \\
\hline Single young adult, 19-20 & 0.001 & $(0.00)$ & 0.003 & $(0.00)$ & $(0.001)$ & $(0.00)$ & $(0.006)$ & $(0.00)$ \\
\hline Single, 18 years & - & - & - & - & - & - & - & - \\
\hline \multicolumn{9}{|l|}{ Enabling factors } \\
\hline Currently insured & 0.030 & $(0.01) *$ & 0.023 & $(0.01) *$ & 0.005 & $(0.00)$ & $(0.004)$ & $(0.00)$ \\
\hline \multicolumn{9}{|l|}{ Public assistance } \\
\hline TANF/CalWorks participation & $(0.000)$ & - & $(0.001)$ & $(0.00)$ & $(0.000)$ & - & 0.000 & - \\
\hline Food stamps participation & $(0.000)$ & - & $(0.000)$ & $(0.00)$ & $(0.000)$ & - & $(0.000)$ & - \\
\hline SSI participation & 0.003 & $(0.00)$ & 0.003 & $(0.00) *$ & 0.000 & $(0.00)$ & $(0.001)$ & $(0.00)$ \\
\hline WIC participation & $(0.000)$ & $(0.00)$ & $(0.001)$ & $(0.00)$ & $(0.001)$ & $(0.00)$ & $(0.000)$ & $(0.00)$ \\
\hline Medical participation & 0.002 & $(0.00)$ & 0.001 & $(0.00)$ & 0.001 & $(0.00)$ & $(0.000)$ & $(0.00)$ \\
\hline \multicolumn{9}{|c|}{ Family poverty level (\% of Federal Poverty Level) } \\
\hline $0-99 \%$ FPL & 0.015 & $(0.01) *$ & 0.007 & $(0.01)$ & $(0.001)$ & $(0.01)$ & $(0.001)$ & $(0.01)$ \\
\hline
\end{tabular}


Table 3 (continued)

\begin{tabular}{|c|c|c|c|c|c|c|c|c|}
\hline & \multicolumn{2}{|l|}{ (1) } & \multicolumn{2}{|l|}{$(2)$} & \multicolumn{2}{|l|}{ (3) } & \multicolumn{2}{|l|}{ (4) } \\
\hline & \multicolumn{2}{|c|}{ Usual source } & \multicolumn{2}{|c|}{ Doctor visit } & \multicolumn{2}{|c|}{ Delay prescr. } & \multicolumn{2}{|c|}{ Delay treatment } \\
\hline & Coef. & SE & Coef. & SE & Coef. & SE & Coef. & SE \\
\hline 100-199 \% FPL & $(0.004)$ & $(0.00)$ & $(0.005)$ & $(0.00)$ & $(0.002)$ & $(0.00)$ & 0.000 & $(0.00)$ \\
\hline 200-299 \% FPL & - & - & - & - & - & - & - & - \\
\hline $300 \%$ FPL and above & $(0.001)$ & $(0.00)$ & 0.000 & $(0.00)$ & $(0.002)$ & $(0.00)$ & 0.002 & $(0.00)$ \\
\hline Household size & 0.000 & $(0.00)$ & $(0.001)$ & $(0.00)$ & $(0.000)$ & $(0.00)$ & 0.000 & $(0.00)$ \\
\hline \multicolumn{9}{|l|}{ Community type } \\
\hline Rural & 0.001 & $(0.00)$ & $(0.000)$ & $(0.00)$ & 0.000 & - & $(0.000)$ & - \\
\hline Urban & $(0.002)$ & $(0.00)$ & $(0.001)$ & $(0.00)$ & $(0.001)$ & $(0.00)$ & $(0.001)$ & $(0.00)$ \\
\hline Suburban & - & - & - & - & - & - & - & - \\
\hline \multicolumn{9}{|l|}{ Need factor } \\
\hline \multicolumn{9}{|c|}{ Self-reported general health status } \\
\hline Excellent & - & - & - & - & - & - & - & - \\
\hline Very good & 0.000 & $(0.00)$ & 0.000 & $(0.00)$ & 0.000 & $(0.00)$ & 0.000 & $(0.00)$ \\
\hline Good & $(0.004)$ & $(0.00)$ & $(0.004)$ & $(0.00)$ & $(0.003)$ & $(0.00)$ & $(0.003)$ & $(0.00)$ \\
\hline Fair & 0.004 & $(0.00)$ & 0.008 & $(0.00) *$ & 0.010 & $(0.00) * *$ & 0.008 & $(0.01)$ \\
\hline Poor & 0.003 & $(0.00)$ & 0.006 & $(0.00) *$ & 0.003 & $(0.00) *$ & 0.003 & $(0.00)$ \\
\hline Observations & 11,481 & & 11,481 & & 11,481 & & 11,481 & \\
\hline
\end{tabular}

${ }^{*} p<0.5 ;{ }^{*} p<0.01 ; * * * p<0.001$

newer immigrants more likely to underutilize health care, but also that their underutilization is statistically significant and driven primarily by their lack of insurance, lack of adequate financial resources, and inability to navigate the health care system due to LEP.

In addition to identifying the difficulties unique to recent immigrants, the results also suggest that nonrecent immigrants who continue to struggle with LEP may also face unique vulnerabilities in accessing and utilizing health services. In fact, non-recent immigrants with LEP were less likely to have a usual source of care and more likely to report delays in obtaining medical treatments, than even recent immigrants with LEP. Although it is beyond the scope of this study, this result raises questions about how and why some immigrants may fail to develop the requisite language proficiency to successfully navigate the health care system over time. It also highlights how difficulties that immigrants face in accessing and utilizing health care are complex, likely consisting of interactions among many factors.

Since insurance status, public assistance participation, poverty level, and LEP are relatively mutable characteristics, the Andersen model suggests that it may be worthwhile to consider policies and interventions to rectify the patterns of inequitable health care underutilization by recent immigrants. These policies would need to focus on increasing insurance access for new immigrants, increasing their access to public assistance (particularly to SSI) participation, and to ensure continued health care support for those struggling with LEP.

Much work still remains, however, in understanding the mechanisms through which a lack of insurance and adequate financial resources, and LEP may lead to underutilization of health services among recent immigrants. The results of this study cannot stipulate, for example, whether recent immigrants simply did not try to access health care services for lack of insurance and adequate financial resources or whether they tried to, but could not obtain, access to those services. Thus, understanding these mechanisms may result in more targeted and effective policies for stimulating equitable health care utilization among immigrants. Similarly, future work may also examine the means through which some immigrants may fail to develop the requisite language proficiency to navigate the US health care system over time.

Although the use of cross-sectional data in the logistic regression analyses precludes causal claims, the decomposition analyses highlight the primary drivers of the health care differences between recent and non-recent immigrants by identifying the factors that explain the majority of the variation between the two groups. To address potential limitations due to multiple comparisons in the univariate descriptive analyses, Holm-adjusted $p$ values were utilized to determine significance in the descriptive analyses, as described in the "Materials and Methods" section above. Additionally, the likelihood ratio tests used to test each of the multivariate 
logistic regression models as a whole confirm the presence of significant predictors in multivariate logistic regression analyses. A potential concern is selection bias from the randomdigit sample employed in the CHIS since only persons with access to landline or cellular phones would have been included in the survey. The CHIS documentation states, however, that the data remains representative of California's noninstitutionalized population and the survey weights designed, among other things, to compensate for households lacking phones were employed throughout the study. Even so, this study includes only immigrants in California so results may not be generalizable to immigrants in other states and contexts.

In summary, this paper contributes to the work on immigrant health care in several ways. First, it examines health care utilization and access among all immigrants in California, not just Asians or Latinos. Consequently, the findings are generalizable to all immigrants in California, rather than those found in specific ethnic subgroups. Secondly, use of the decomposition method allows identification of the primary drivers of healthcare differences between recent and nonrecent immigrants, rather than merely identifying factors associated with their health care use. Finally, the study employs the 2009 CHIS data, one of the largest state health surveys in the nation and containing nearly 11,500 immigrants. Use of this representative and extensive data affords sound and reliable inference on California's growing and diverse immigrant population.

Acknowledgments This study was partially funded through the generous support of the W.K. Kellogg Foundation and the UCLA Luskin School of Public Affairs. Jocelyn Chi also gratefully acknowledges support from the Luskin, Community Partners, Calvin and Marilyn Gross, and Bette Hans Lorenz fellowships at the UCLA Luskin School of Public Affairs. We also thank Gilbert Gee, Neely Atkinson, and Eric Chi for many helpful comments and discussions. Finally, we thank the anonymous reviewers for feedback and suggestions that greatly improved the quality of the manuscript.

Ethical Statements Jocelyn Chi and Mark Handcock declare that they have no conflicts of interest. All procedures followed were in accordance with the ethical standards of the responsible committee on human experimentation (institutional and national) and with the Helsinki Declaration of 1975, as revised in 2000 (5). Informed consent was obtained from all patients for inclusion in the study.

\section{References}

1. Aday LA, Andersen R. A framework for the study of access to medical care. Health Serv Res. 1974;9(3):208-20.

2. Andersen RM. Revisiting the behavioral model and access to medical care - does it matter. J Health Soc Behav. 1995;36(1):1-10. doi:10. 2307/2137284.

3. Aroian KJ, Wu B, Tran TV. Health care and social service use among Chinese immigrant elders. Res Nurs Health. 2005;28(2):95-105. doi: 10.1002/nur.20069.
4. Asanin J, Wilson K. "I spent nine years looking for a doctor": exploring access to health care among immigrants in Mississauga, Ontario, Canada. Soc Sci Med. 2008;66(6):1271-83. doi:10.1016/j. socscinied.2007.11.043.

5. Bischoff A, Perneger TV, Bovier PA, Loutan L, Stalder H. Improving communication between physicians and patients who speak a foreign language. Br J Gen Pract. 2003;53(492):541-6.

6. Bollinger CR, Hagstrom P. Food stamp program participation of refugees and immigrants. South Econ J. 2008;74(3):665-92.

7. Borjas GJ. Welfare reform and immigrant participation in welfare programs. Int Migr Rev. 2002;36(4):1093-123.

8. Borjas GJ. Food insecurity and public assistance. J Public Econ. 2004;88(7-8):1421-43. doi:10.1016/s0047-2727(02)00188-3.

9. Borjas GJ, Hilton L. Immigration and the welfare state: immigrant participation in means-tested entitlement programs. Q J Econ. 1996;111(2):575-604. doi:10.2307/2946688.

10. Bustamante AV, Fang H, Garza J, Carter-Pokras O, Wallace SP, Rizzo $\mathrm{JA}$, et al. Variations in healthcare access and utilization among Mexican immigrants: the role of documentation status. J Immigr Minor Health. 2012;14(1):146-55. doi:10.1007/s10903-010-9406-9.

11. California Health Interview Survey. (2011). CHIS 2009 Methodology Series: Report 4-Response Rates.

12. California Health Interview Survey. (November 2011a). California Health Interview Survey 2009 Data Dictionary.

13. California Health Interview Survey. (November 2011b). Chis 2009 Methodology Series. Retrieved October, 2012.

14. Cotton J. On the decomposition of wage differentials. Rev Econ Stat. 1988;70:236-43.

15. Deri C. Social networks and health service utilization. J Health Econ. 2005;24(6):1076-107. doi:10.1016/j.jhealeco.2005.03.008.

16. Derose KP, Bahney BW, Lurie N, Escarce JJ. Immigrants and health care access, quality, and cost. Med Care Res Rev. 2009;66(4):355408. doi:10.1177/1077558708330425.

17. Derose KP, Escarce JJ, Lurie N. Immigrants and health care: sources of vulnerability. Health Aff. 2007;26(5):1258-68. doi:10.1377/ hlthaff.26.5.1258.

18. Durden TE. Usual source of health care among Hispanic children the implications of immigration. Med Care. 2007;45(8):753-60. doi: 10.1097/MLR.0b013e318054688e.

19. Elder T, Goddeeris JH, Haider SJ. Unexplained gaps and Oaxacablinder decompositions. Labour Econ. 2010;17(1):284-90.

20. Fairlie RW. An extension of the Blinder-Oaxaca decomposition technique to logit and probit models. J Econ Soc Meas. 2005;30: 305-16.

21. Fiscella K, Franks P, Doescher MP, Saver BG. Disparities in health care by race, ethnicity, and language among the insured - findings from a national sample. Med Care. 2002;40(1):52-9. doi:10.1097/ 00005650-200201000-00007.

22. Fox J, Monette G. Generalized collinearity diagnostics. J Am Stat Assoc. 1992;87(417):178-83.

23. Fox, J. \& Weisberg, S. (2011). An R companion to applied regression, Second Edition. Thousand Oaks CA: Sage. URL: http://socserv. socsci.mcmaster.ca/jfox/Books/Companion.

24. Frisbie WP, Cho YT, Hummer RA. Immigration and the health of Asian and Pacific Islander adults in the United States. Am J Epidemiol. 2001;153(4):372-80.

25. Goldman DP, Smith JP, Sood N. Legal status and health insurance among immigrants. Health Aff. 2005;24(6):1640-53. doi:10.1377/ hlthaff.24.6.1640.

26. Hargraves JL, Hadley J. The contribution of insurance coverage and community resources to reducing racial/ethnic disparities in access to care. Health Serv Res. 2003;38(3):809-29. doi:10.1111/1475-6773. 00148.

27. Hernandez-Plaza S, Pozo C, Alonso-Morillejo E. The role of informal social support in needs assessment: proposal and application of a model to assess immigrants' needs in the south of Spain. J 
Community Appl Soc Psychol. 2004;14(4):284-98. doi:10.1002/ casp.782.

28. Holm S. A simple sequentially rejective multiple test procedure. Scand J Stat. 1979;6(2):65-70.

29. Imai, K., King, G., \& Lau, O. (2007). Zelig: Everyone's Statistical Software. http://gking.harvard.edu/zelig.

30. Jann, B. (May 2008). A Stata implementation of the Blinder-Oaxaca decomposition ETH Zurich Sociology Working Papers. Sociology. ETH Zurich.

31. Lai DWL, Chau SBY. Predictors of health service barriers for older Chinese immigrants in Canada. Health Soc Work. 2007;32(1):57-65.

32. Lasser KE, Himmelstein DU, Woolhandler S. Access to care, health status, and health disparities in the United States and Canada: results of a cross-national population-based survey. Am J Public Health. 2006;96(7):1300-7. doi:10.2105/ajph.2004.059402.

33. Lebrun LA. Effects of length of stay and language proficiency on health care experiences among Immigrants in Canada and the United States. Soc Sci Med. 2012;74(7):1062-72. doi:10.1016/j.socscimed. 2011.11.031.

34. Lumley T. Analysis of complex survey samples. J Stat Software. 2004;9(1):1-19.

35. Machado JAF. Counterfactual decomposition of changes in wage distributions using quantile regression. J Appl Econ. 2005;20:445-65.

36. Makepeace G, Paci P, Joshi H, Dolton P. How unequally has equal pay progressed since the 1970s? A study of two British cohorts. J Human Resour. 1999;34:534-56.

37. McLafferty S, Grady S. Immigration and geographic access to prenatal clinics in Brooklyn, NY: a geographic information systems analysis. Am J Public Health. 2005;95(4):638-40. doi:10.2105/ ajph.2003.033985.

38. Neumark D. Employers' discriminatory behavior and the estimation of wage discrimination. J Human Resour. 1988;23:279-95.

39. Ponce NA, Chawla N, Babey SH, Gatchell MS, Etzioni DA, Spencer BA, et al. Is there a language divide in Pap test use? Med Care. 2006;44(11):998-1004. doi:10.1097/01.mlr.0000233676.61237.ef.
40. R Core Team. R: a language and environment for statistical computing. Vienna: R Foundation for Statistical Computing; 2012.

41. Salinero-Fort MA, del Otero-Sanz L, Martin-Madrazo C, de BurgosLunar C, Chico-Moraleja RM, Rodes-Soldevila B, et al. The relationship between social support and self-reported health status in immigrants: an adjusted analysis in the Madrid Cross Sectional Study. Bmc Fam Pract. 2011;12:9. doi:10.1186/1471-2296-12-46.

42. StataCorp. (2011). Stata statistical software: Release 12. http://www. stata.com.

43. Steele LS, Lemieux-Charles L, Clark JP, Glazier RH. The impact of policy changes on the health of recent immigrants and refugees in the inner city - a qualitative study of service providers' perspectives. Can J Public Health-Revue Canadienne De Sante Publique. 2002;93(2): 118-22.

44. Stewart DE, Do BN. Health needs of migrant Vietnamese women in south-west Brisbane: an exploratory study. Aus J Soc Issues. 2003;38(2):247-61.

45. Waidmann TA, Rajan S. Race and ethnic disparities in health care access and utilization: an examination of state variation. Med Care Research and Review. 2000;57:55-84. doi:10.1177/ 107755800773743600.

46. Wu Z, Penning MJ, Schimmele CM. Immigrant status and unmet health care needs. Can J Public Health-Rev Canadienne De Sante Publique. 2005;96(5):369-73.

47. Ye JL, Mack D, Fry-Johnson Y, Parker K. Health care access and utilization among US-born and foreign-born Asian Americans. J Immigr Minor Health. 2012;14(5):731-7. doi:10.1007/s10903-0119543-9.

48. Yu SM, Huang ZJ, Singh GK. Health status and health services access and utilization among Chinese, Filipino, Japanese, Korean, south Asian, and Vietnamese children in California. Am J Public Health. 2010;100(5):823-30. doi:10.2105/ajph.2009.168948.

49. Zuvekas SH, Tallaferro GS. Pathways to access: health insurance, the health care delivery system, and racial/ethnic disparities, 1996-1999. Health Aff. 2003;22(2):139-53. doi:10.1377/hlthaff.22.2.139. 